\title{
Modulation of Multiple Precipitates for High Strength and Ductility in Al-Cu-Mn Alloy
}

\author{
Linxiang Liu, Zhijun Wang *, Qingfeng Wu, Zhongsheng Yang ${ }^{(0)}$, Kexuan Zhou, Xiaoguang Fan, Junjie Li \\ and Jincheng Wang *
}

check for updates

Citation: Liu, L.; Wang, Z.; Wu, Q.;

Yang, Z.; Zhou, K.; Fan, X.; Li, J.;

Wang, J. Modulation of Multiple

Precipitates for High Strength and

Ductility in Al-Cu-Mn Alloy.

Materials 2021, 14, 7383. https://

doi.org/10.3390/ma14237383

Academic Editor: Adam Grajcar

Received: 10 November 2021

Accepted: 27 November 2021

Published: 2 December 2021

Publisher's Note: MDPI stays neutral with regard to jurisdictional claims in published maps and institutional affiliations.

Copyright: (c) 2021 by the authors. Licensee MDPI, Basel, Switzerland. This article is an open access article distributed under the terms and conditions of the Creative Commons Attribution (CC BY) license (https:/ / creativecommons.org/licenses/by/ $4.0 /)$.
State Key Laboratory of Solidification Processing, Northwestern Polytechnical University, Xi'an 710072, China; lxliu@mail.nwpu.edu.cn (L.L.); qingfengwu@mail.nwpu.edu.cn (Q.W.); zsyang@mail.nwpu.edu.cn (Z.Y.); kx_zhou@mail.nwpu.edu.cn (K.Z.); fxg3200@nwpu.edu.cn (X.F.); lijunjie@nwpu.edu.cn (J.L.)

* Correspondence: zhjwang@nwpu.edu.cn (Z.W.); jchwang@nwpu.edu.cn (J.W.)

Abstract: The category and morphology of precipitates are essential factors in determining the mechanical behaviors of aluminum alloys. It is a great challenge to synthetically modulate multiple precipitates to simultaneously improve strength and ductility. In the present work, by optimizing the precipitations of the GP zone, $\theta^{\prime}$-approximant and $\theta^{\prime}$ phase for an Al-Cu-Mn alloy, a high tensile strength of $585 \mathrm{MPa}$ with large elongation of $12.35 \%$ was achieved through pre-deformation and aging. The microstructure evolution pattern was revealed by detailed characterizations of scanning electron microscopy and transmission electron microscopy. It was found that such high tensile strength of the samples was due to a combination of strengthening by the high density of dispersive fine precipitates and dislocations, and the high elongation to failure was primarily attributed to the multimodal precipitates and elimination of precipitation-free zones along the grain boundaries. The strategy proposed here is a promising way of preparing ultra-strong $\mathrm{Al}-\mathrm{Cu}-\mathrm{Mn}$ alloys.

Keywords: aluminum alloys; pre-deformation; mechanical properties; strengthening mechanisms

\section{Introduction}

Aluminum-copper alloys have been widely developed and used in the fields of aerospace and transportation due to their low density and high strength [1]. Typically, as an Al-Cu-Mn alloy, the 2219 alloy is extensively exploited and used as a structural material in the aerospace industry, such as transition rings constituting a tube, short shells, and a dome of tanks, because of its excellent mechanical properties over a wide temperature range and good weldability [2]. Similarly, with a proper combination of mechanical properties, ballistic resistance and resistance to stress corrosion cracking, the 2519 alloy and its upgrade version, 2519A, have been widely used in naval structures, such as advanced amphibious assault vehicles (AAAVs) [3]. Similar to the 2219 alloy, the ZL205A alloy is a casting Al-Cu-Mn alloy that has outstanding mechanical properties, and it has been widely applied in aircraft frame components. Its ultimate tensile strength can exceed $500 \mathrm{MPa}$ after T6 treatment. To date, most of the research has focused on the traditional microalloying [4-6] or optimization of the solidification process [7-11] to further improve the strength of ZL205A as a casting alloy.

For ultra-strong aluminum alloy, ultra-fine grains (UFGs) produced by severe plastic deformation (SPD) are attracting increasing attention [12]. Numerous methods for SPD processing are now available for wrought aluminum alloy, such as equal-channel angular pressing (ECAP) [13-15], high pressure torsion (HPT) [16], cryorolling [17] and accumulative roll bonding (ARB) [18]. Guo et al. [19] systematically investigated the evolution of microstructure of the ZL205A alloy during ECAP at room temperature, illustrating that the hardness of the heat-treated ZL205A alloy increased from $112 \mathrm{HV}$ to $198 \mathrm{HV}$ after two passes of ECAP. However, in the consideration of the diminishing strain hardening capacity 
in UFG materials, low ductility under ambient conditions would be the challenge to be overcome [20-22].

In contrast, thermo-mechanical treatment (TMT) such as the T8 series has caught increasing attention in industrial manufacturing. For instance, the mechanical performances of Al-Cu-Mn alloys can be improved by tailoring their precipitation behaviors in TMT. In addition, it has been reported that pre-deformation can optimize aging precipitation behavior and improve the strength of the 2219 alloy [23-25]. Li et al. [26] subjected 2219 alloy samples to $8.0 \%$ pre-stretch before aging, resulting in a $22 \%$ increase in yield strength because of the deformation-ameliorated precipitation distribution. When the pre-deformation degree was increased to $80 \%$, a $130 \mathrm{MPa}$ strength improvement without loss of ductility came to the heavily rolled $\mathrm{Al}-\mathrm{Cu}$ alloy after subsequent low-temperature aging. This is due to the dislocation hardening and precipitation strengthening by a kind of fine coherent $\theta^{\prime}$-approximant [27]. The nucleation sites from the generated dislocation in the pre-deformation step can promote precipitation or even change the sequences of multiple precipitates.

To date, the precipitation behavior in the ZL205A alloy under TMT has lacked attention. The appropriate aging treatment with pre-deformation could be an effective way of designing the bimodal microstructure of precipitation in $\mathrm{Al}-\mathrm{Cu}$ alloys [28]. In view of the ZL205A alloy being a candidate for a structural material with high strength and ductility, we obtained excellent strength and ductility in the ZL205A alloy by developing a TMT procedure to control precipitation behaviors. Both ductility and strength are superior among the reported Al-Cu-Mn alloys. The strategy was systematically optimized by adjusting the solution treatment, large cold deformation and aging treatment. The microstructure evolution was analyzed using scanning electron microscopy (SEM) and transmission electron microscopy (TEM).

\section{Experiments}

In this work, a commercial ZL205A alloy ingot is used, whose composition is listed in Table 1. The ingot was firstly solution treated at $538{ }^{\circ} \mathrm{C}$ for $15 \mathrm{~h}$ and then waterquenched into room temperature (RT) to form the solid solution samples with coarse grains. Then, a conventional T6 treatment was applied for comparison (aging at $160{ }^{\circ} \mathrm{C}$ ). For TMT, the thickness reductions for RT cold rolling were $70 \%, 80 \%$ and $90 \%$, respectively. Different aging conditions were then applied at $120^{\circ} \mathrm{C}$ or $160^{\circ} \mathrm{C}$ for $0-24 \mathrm{~h}$ to optimize the strength/ductility combination.

Table 1. Chemical composition of ZL205A Al-Cu alloy (wt.\%).

\begin{tabular}{cccccccccc}
\hline $\mathbf{C u}$ & $\mathbf{M n}$ & $\mathbf{T i}$ & $\mathbf{Z r}$ & $\mathbf{C d}$ & $\mathbf{B}$ & $\mathbf{V}$ & Si & Fe & Al \\
\hline 4.98 & 0.39 & 0.24 & 0.12 & 0.21 & 0.028 & 0.13 & 0.021 & 0.026 & Bal \\
\hline
\end{tabular}

Vickers hardness (300 g load with $15 \mathrm{~s}$ dwell time) measurements were carried out on the cold rolled, annealed and aged samples to assess the strength. At least five data points were recorded to obtain the average hardness value of each sample. Uniaxial tensile tests were performed at strain rates of $10^{-3} \mathrm{~s}^{-1}$ on samples that were cut along the rolling direction and polished into dog-bone shapes with a gauge length of $12.5 \mathrm{~mm}$. All the tests were performed at least three times in order to ensure the repeatability and reproducibility of the results.

X-ray diffraction (XRD) measurements $\left(2 \theta\right.$ from $20^{\circ}$ to $\left.100^{\circ}\right)$ were carried out on Rigakud/max-2550 with a monochromator. The scanning step was $0.02^{\circ}$, and the scanning rate was $5^{\circ}$ per min. Microstructure characterization was performed using TEM (JEOL 2100 F, JEOL, Tokyo, Japan) and SEM (Tescan Mira 3, Tescan, Brno, The Czech Republic) equipped with back scattered electron (BSE) detector. The SEM specimens were prepared by grinding the samples with abrasive papers, and, subsequently, they were subjected to electropolishing with the solution of $30 \%$ perchloric acid in ethanol. All of the TEM 
specimens were prepared by twin-jet polishing with a solution of $30 \%$ nitric acid and $70 \%$ methanol at $-30^{\circ} \mathrm{C}$ and $20 \mathrm{~V}$.

\section{Results and Discussion}

\subsection{Evolution of Mechanical Properties during Different Processing Stages}

Figure 1 displays the Vickers hardness variation as a function of time for different treatments on the ZL205A alloy. As shown in Figure 1a, the hardness of the T6processed sample increased to a plateau of $\sim 160 \mathrm{HV}$ after $10 \mathrm{~h}$ aging. After large pre-deformation, the hardness of the samples increased sharply, and the largest hardness value of the $90 \%$ rolled sample ( $172 \mathrm{HV})$ was much greater than that of the solid solution state. Compared with the conventional T6-processed sample, the hardness decreased rapidly with the extension of aging time at $160{ }^{\circ} \mathrm{C}$. Both $160^{\circ} \mathrm{C}$ and $120^{\circ} \mathrm{C}$ are common aging temperatures for the ZL205A Al-Cu alloy [27]. Theoretically, aging at $160^{\circ} \mathrm{C}$ could accelerate the precipitation kinetics after large pre-deformation, leading to more dispersive fine precipitates and higher hardness at the early stage. However, the hardness of the deformed sample decreases continuously at $160^{\circ} \mathrm{C}$. When heating a largely deformed supersaturated alloy, there will be a competitive phenomenon between recovery/recrystallization and precipitation. In general, at relatively higher temperatures, the recovery/recrystallization starts earlier before there is significant precipitation. Therefore, the reason for the decreasing hardness at the early stage could be interpreted as due to the descent of dislocation density brought by the quicker recovery/recrystallization. A similar phenomenon could also be observed in the results of Ma et al.'s study [27], where a quicker decrease in hardness was found at the same deformation degree. Thus, it could be deduced that the temperature of aging should be relative lower for the sample that underwent large pre-deformation. As shown in Figure 1b, we subsequently aged the sample after large pre-deformation at $120^{\circ} \mathrm{C}$, finding that the samples with different pre-deformation degrees exhibited various evolution tendencies of hardness. When aging at $120^{\circ} \mathrm{C}$, the hardness of the $70 \%$ cold-rolled sample increased from $147 \mathrm{HV}$ to the maximum of $172 \mathrm{HV}$ for $15 \mathrm{~h}$, followed by a sharp decrease. Intriguingly, for the $80 \%$ cold-rolled sample, the hardness maintained moderate fluctuation with a peak-aged stage $(\sim 175 \mathrm{HV})$ at $12 \mathrm{~h}$. An evident drop occurred before the hardness of the $90 \%$ cold-rolled sample fluctuated in a relatively stable range around $160 \mathrm{HV}$.
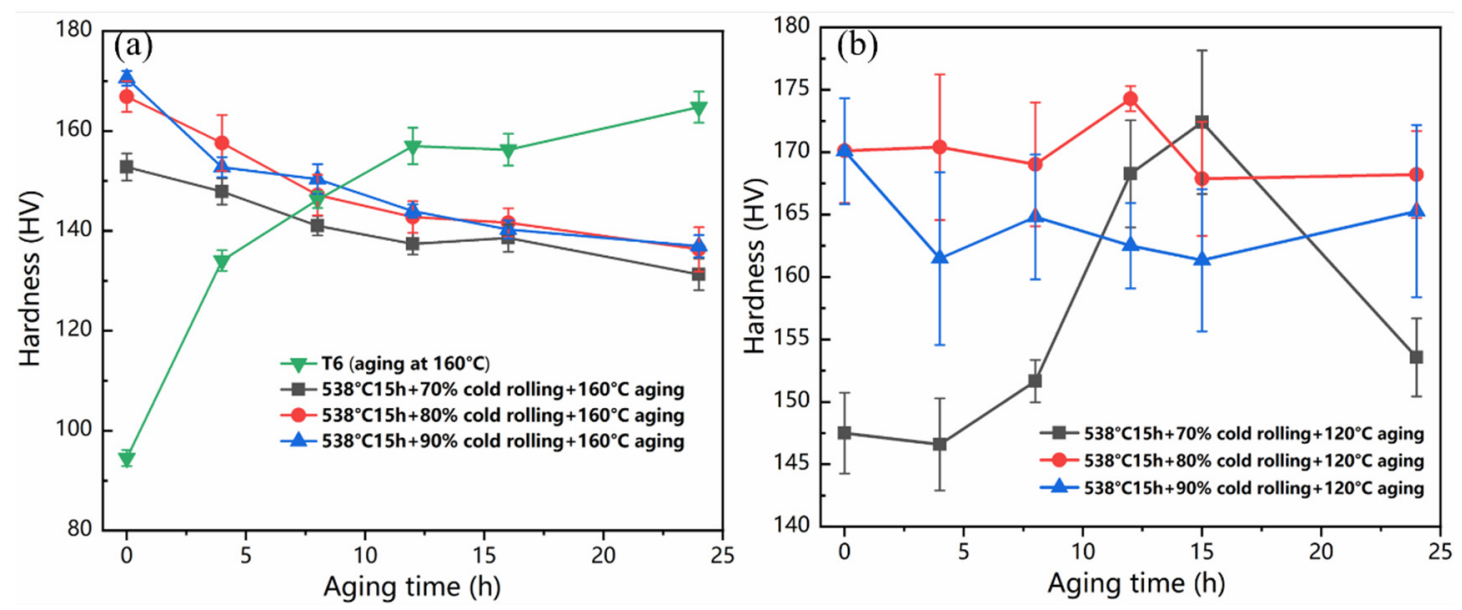

Figure 1. Variation of Vickers hardness during aging for samples subjected to (a): T6 and aging at $160{ }^{\circ} \mathrm{C}$ after $70-90 \%$ cold rolling and (b) aging at $120^{\circ} \mathrm{C}$ after $70-90 \%$ cold rolling.

Based on the hardness evolution during the aging process, room-temperature tensile tests were carried out to reveal the evolution of the mechanical properties. Figure 2a plots the typical stress-strain curves of the ZL205A alloy under different processing states. The as-cast sample has a yield strength (YS) of $\sim 110 \mathrm{MPa}$, an ultimate tensile strength (UTS) of $\sim 240 \mathrm{MPa}$ and an elongation to failure (ETF) close to $11 \%$. After solution treatment 
at $538^{\circ} \mathrm{C}$ for $15 \mathrm{~h}$, both the tensile strength and ductility of the sample were improved. The strength of the peak-aged T6 sample was substantially increased (YS 421 MPa and UTS $508 \mathrm{MPa}$ ) by precipitation strengthening, with an ETF close to $9.4 \%$. The strength of $70 \%$ and $80 \%$ cold-rolled samples significantly increased, while the ductility reduced sharply, especially for the poor uniform elongation, which is typical for cold-worked metals. As the aging temperature for $\mathrm{Al}-\mathrm{Cu}$ alloy is low, cold rolling could take effect in natural aging to accelerate it. Therefore, besides the high-density dislocations, the hardening effect could partially be attributed to the natural aging in the cold-rolled sample. Generally, and significantly, aging cold-rolled samples can remarkably enhance their tensile ductility while keeping or even modestly increasing strength via precipitation hardening. Therefore, there were excellent mechanical properties of the samples subjected to $70 \%$ and $80 \%$ cold rolling, which were designated as P70A-120 and P80A-120 for further discussion, respectively. In Figure 2a, it could be found that the ETFs of these two samples were notably increased. The P80A-120 sample yielded higher strength (YS 524 MPa and UTS 585 MPa) than that of the P70A-120 sample (YS 508 MPa and UTS 569 MPa), while its ETF ( 12.3\%) was slightly lower than that of the P70A-120 sample ( 16.3\%). Both of these samples exhibited better mechanical properties than those of the T6 sample by overcoming the strength-ductility trade-off. In addition, a comparison of the mechanical properties of the reported $\mathrm{Al}-\mathrm{Cu}-\mathrm{Mn}$ series alloys under various processing methods is illustrated in Figure 2b. The present work presents the superior mechanical properties among the samples subjected to conventional T6 treatment, mild pre-deformation and SPD such as cryorolling.
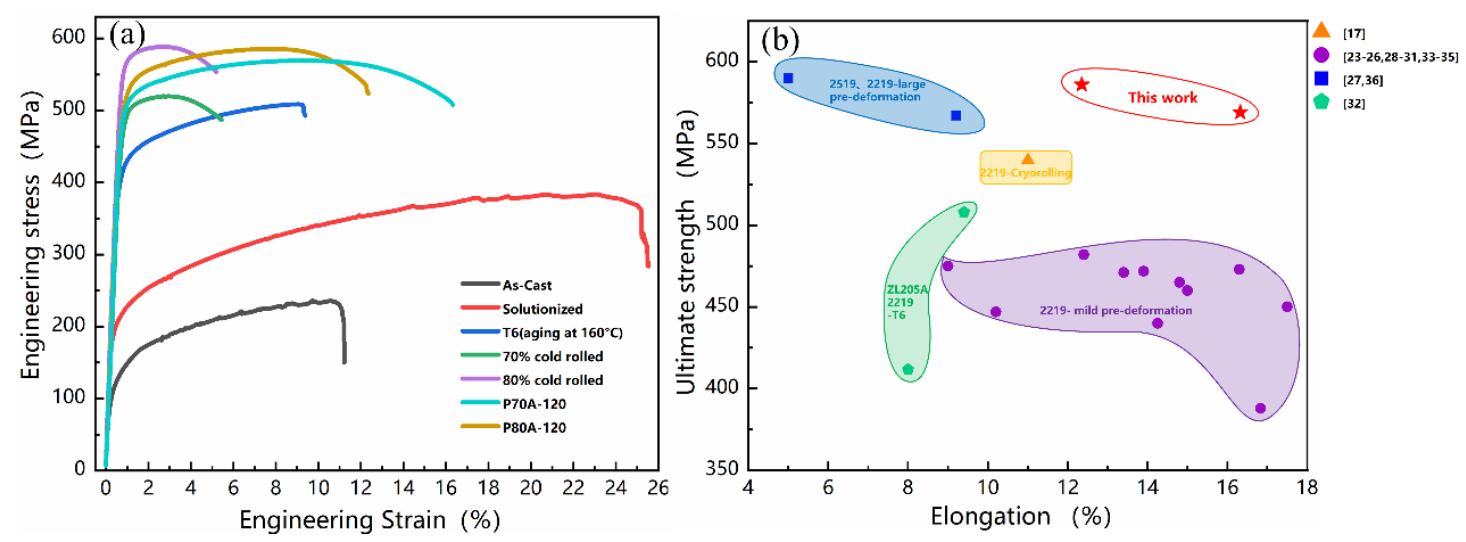

Figure 2. (a) Tensile engineering stress-strain curves of samples under different processing states; (b) the map of ultimate tensile strength-ductility combinations of existing Al-Cu-Mn alloy research [17,23-27,29-37], including our work.

\subsection{Evolution of Microstructure in Different Processing Stages}

The microstructure and corresponding XRD patterns of the as-cast, solutionized, T6, P70A-120, and P80A-120 samples are presented in Figures 3 and 4, respectively. Figure 3a demonstrates the microstructure of the as-cast ZL205A alloy containing equiaxed grains (average size $\sim 60 \mu \mathrm{m}$ ). According to the $\mathrm{XRD}$ patterns shown in Figure 4 , there exist a significant number of eutectic colonies, $(\mathrm{Al})+\mathrm{Al}_{2} \mathrm{Cu}$, around the grain boundaries, which is consistent with the cast microstructure of the 2219 alloy [38]. The homogenization treatment will cause dissolution of eutectic phases. After solution treatment at $538^{\circ} \mathrm{C}$ for $15 \mathrm{~h}$, it can be seen in Figure $3 \mathrm{~b}$ that most of the eutectics dissolved into the matrix, with a minority remaining at the grain boundaries, in accordance with the disappearance of the peak of the $\mathrm{Al}_{2} \mathrm{Cu}$ phase in the XRD pattern. Furthermore, as shown in the inset of Figure $3 \mathrm{~b}$, the rod-like ternary $\mathrm{T}$ phase $\left(\mathrm{Al}_{20} \mathrm{Cu}_{2} \mathrm{Mn}_{3}\right)$ precipitated inside the grains during homogenization, which effectively promotes the accumulation of dislocations during the large deformation process [39]. In contrast, after conventional T6 treatment, there was a coarse second phase larger than $1 \mu \mathrm{m}$ located at the triple junction, and many particles were distributed uniformly inside the grains. 


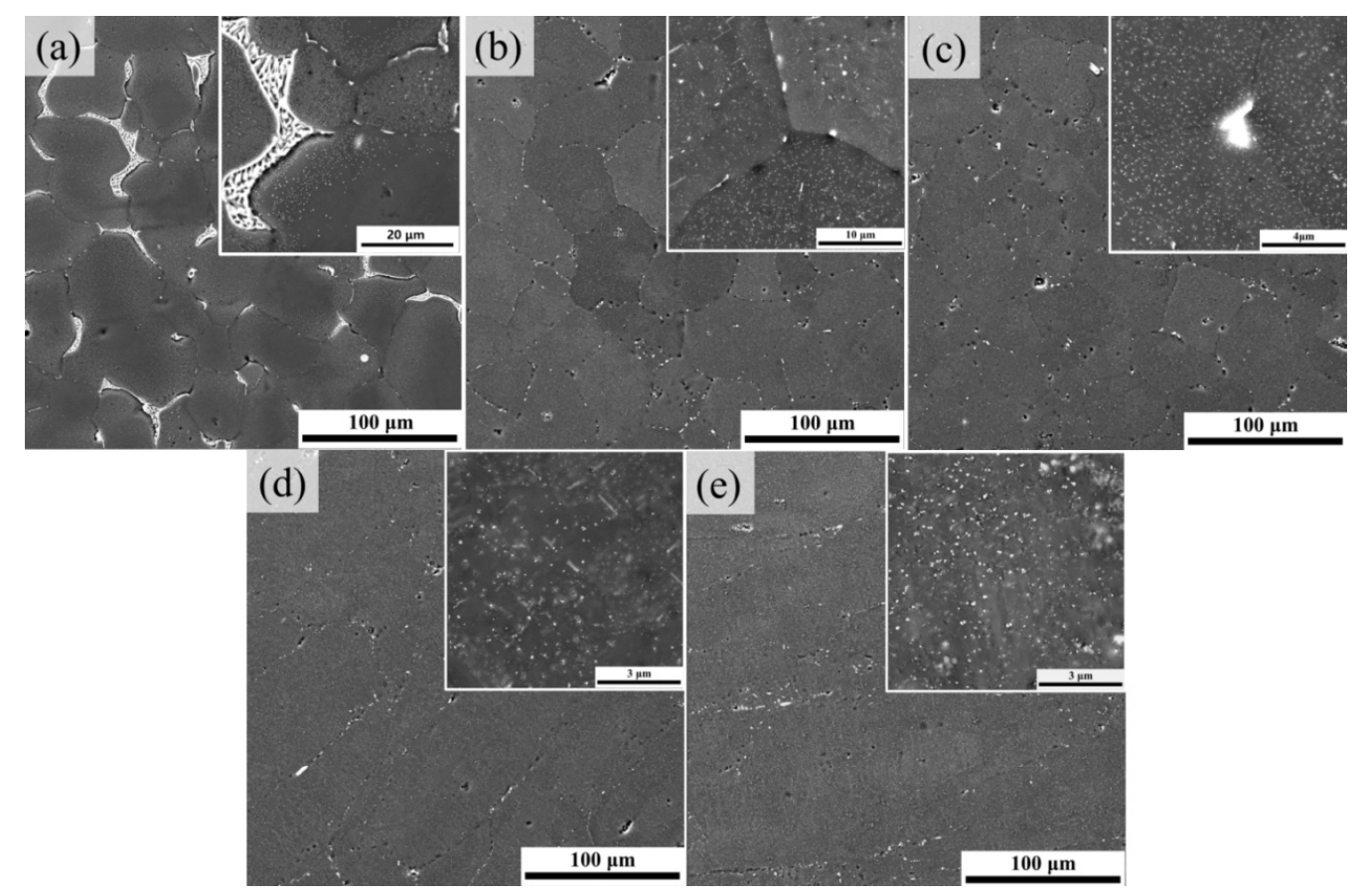

Figure 3. BSE images of the (a) as-cast state, (b) solutionized state, (c) T6 state, (d) P70A120 state and (e) P80A-120 state.

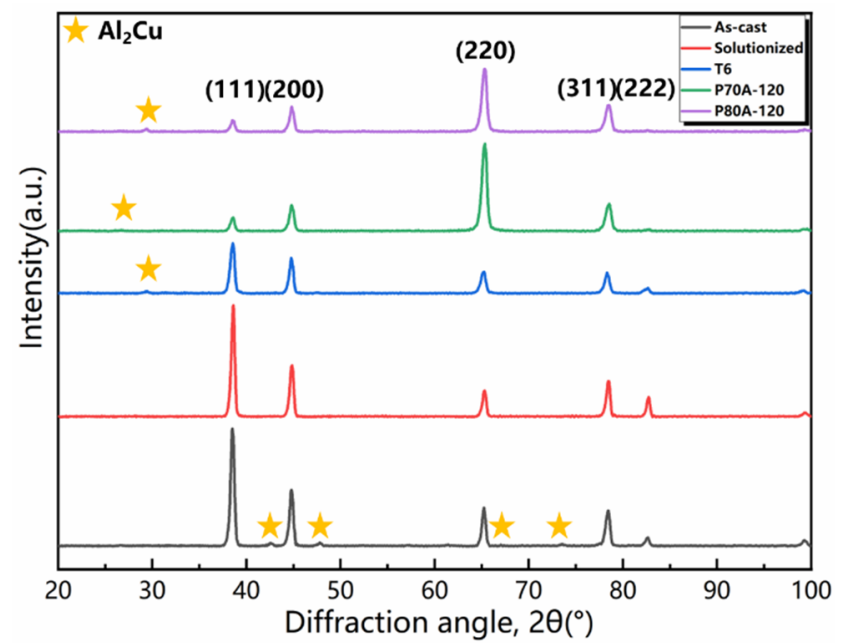

Figure 4. XRD patterns of the as-cast, solutionized, T6, P70A-120 and P80A-120 state.

For the P70A-120 (Figure 3d) and P80A-120 (Figure 3e) samples, the grains were stretched along the rolling direction, with the remnant broken second phase distributing along the prolonged grain boundaries. Additionally, the inset of Figure $3 \mathrm{~d}$ shows that the P70A-120 sample contained numerous fine particles and a certain amount of $\mathrm{T}$ phases with a length of approximately $1 \mu \mathrm{m}$. Similarly, the inset of Figure 3e shows that massive dispersoids distributed homogeneously all over the grains. According to the XRD patterns plotted in Figure 4, the three peak-aged samples with different pre-deformation degrees had the same diffraction peaks of the $\mathrm{Al}_{2} \mathrm{Cu}$ phase, identifying the second phase particles observed in Figure 3c-e. Moreover, for the T6 sample the strongest peak of the Al matrix in the map appeared at the angle of $38^{\circ}$, while that of the P70A-120 and P80A-120 samples changed to $65^{\circ}$. The strongest peaks of $38^{\circ}$ and $65^{\circ}$ correspond to the (111) and (220) crystal planes respectively, and the (220) crystal planes equate to the (110) crystal planes. The (111) crystal planes are the glide planes that most likely glide along the $<110>$ crystal orientation. 
The change in crystal planes indicates that the grain was sliding during pre-deformation to some extent [28], and the P70A-120 and P80A-120 samples could have a texture.

Figure 5 presents the TEM images of the peak-aged T6, P70A-120 and P80A-120 samples with the electron beam parallel to $\{001\}_{\mathrm{Al}}$. As shown in Figure 5a, there are numerous orthogonal needle-like precipitates widely distributed along the $\{001\}_{\mathrm{Al}}$ planes in the matrix. The corresponding selected area electron diffraction (SAED) pattern in the inset of Figure 5a clearly exhibits additional diffraction patterns at the $\{110\}_{\mathrm{Al}}$ positions, implying that the microstructures of these samples mostly consisted of the $\theta^{\prime}$ phase. These features are in agreement with previous reports of a $\theta^{\prime}$ phase formed after T6 treatment of Al-Cu alloys [40,41]. In Figure 5b, the average length and width of the $\theta^{\prime}$ phases were about $100 \mathrm{~nm}$ and $16 \mathrm{~nm}$, respectively. Evidently, the rod-like T-phase had a length and width of approximately $1.3 \mu \mathrm{m}$ and $0.1 \mu \mathrm{m}$, respectively. Additionally, precipitation-free zones (PFZs) about $70 \mathrm{~nm}$ wide and coarse $\mathrm{Al}_{2} \mathrm{Cu}$ particles along the grain boundary were observed in the sample subjected to the $\mathrm{T} 6$ process at $160^{\circ} \mathrm{C}$, as marked in Figure 5c. The direct reason for the occurrence of PFZs is the lack of solutes inside the grains. In general, after high-temperature solution treatment, alloys contain a high concentration of unstable vacancies, which diffuse to the grain boundaries. Since there is high affinity between vacancies and solute atoms [42], there also exists the solute diffusion accompanied by vacancies, which can explain the lack of solutes inside.
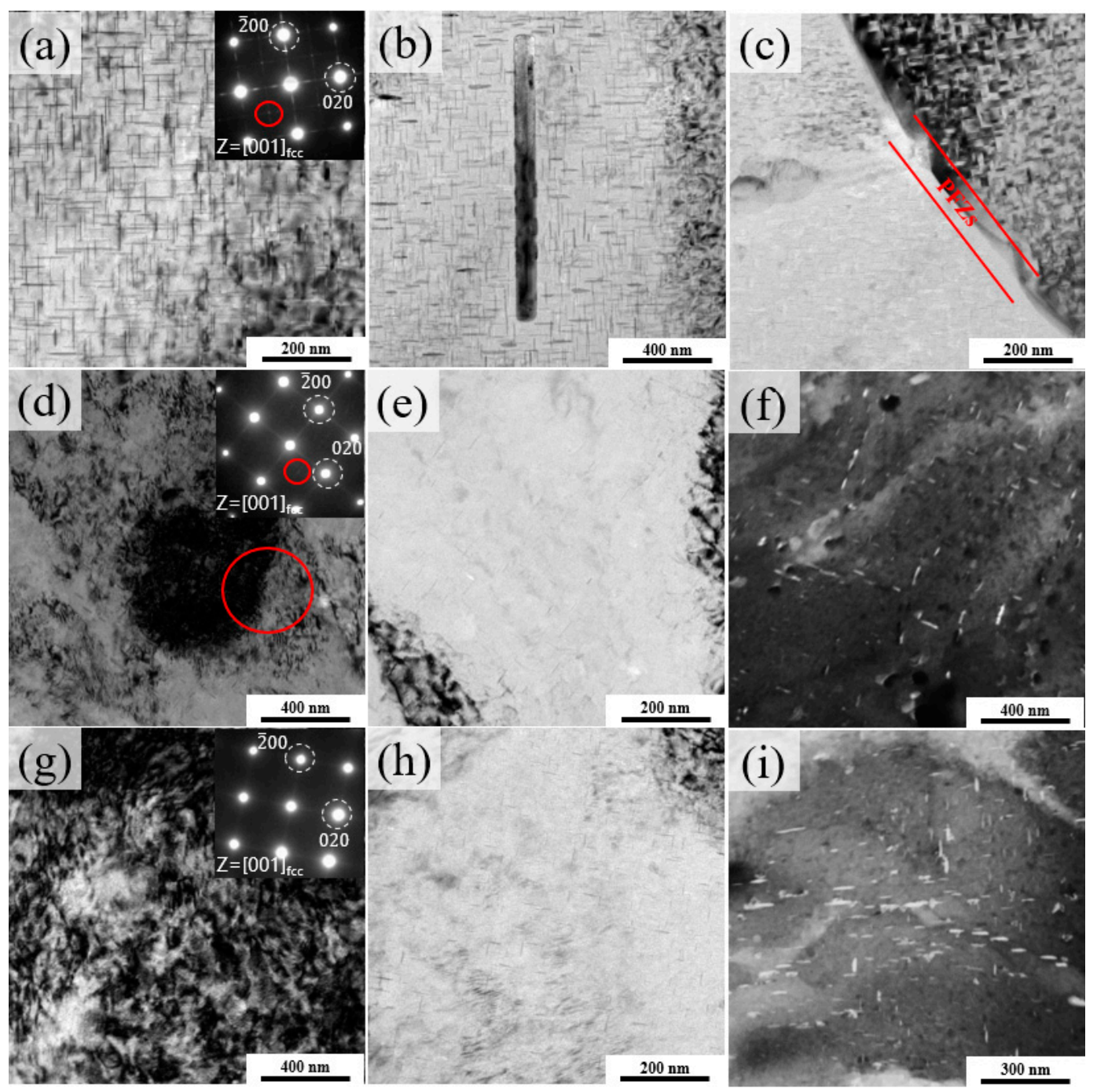

Figure 5. TEM images of the T6 sample: (a-c) BF image with diffraction pattern; P70A-120 sample: (d,e) BF image with diffraction pattern and (f) STEM image; and P80A-120 sample:(g,h) BF image with diffraction pattern and (i) STEM image. 
Figure $5 \mathrm{~d}$ shows the bright field (BF) image along a zone axis close to $\{001\}_{\mathrm{Al}}$ with a corresponding SAED pattern of the P70A-120 sample. It can be seen that after peak aging the sample still contained a high density of dislocation tangles with a few of the precipitates around them, and the diffraction patterns of the $\theta^{\prime}$ phase were obscure because of the strain fields of residual dislocations. Moreover, the precipitates were hardly to be observed in the situation with fewer dislocations as marked in Figure 5d. A region with a low density of dislocations was selected as shown in Figure 5e, and there were a few fine but sparse precipitates on the matrix. Similarly, in the view of scanning TEM (STEM) mode (Figure 5f), it could still be observed that those fine precipitates were distributed non-uniformly. In comparison, the density of remnant dislocations was more uniform and denser in the P80A-120 sample (Figure 5g), resulting in the invisibility of SAED patterns of the $\theta^{\prime}$ phase. The precipitates also became denser at a closer inspection (Figure 5h), indicating that the quantity and uniformity of precipitates increased. In addition, in STEM mode (Figure 5i), it can be observed that the distribution of precipitates was dispersive, and the width of precipitates ranged from $2 \mathrm{~nm}$ to $16 \mathrm{~nm}$ and the length ranged from $11 \mathrm{~nm}$ to $70 \mathrm{~nm}$. In view of the XRD patterns, the observed precipitates with large size in Figure 5f,i could mostly be the $\theta^{\prime}$ phases.

To better characterize the morphology and distribution of the second phase, the precipitates in the P80A-120 sample were characterized in detail by HAADF-STEM. As shown in Figure 6a, the microstructure of the P80A-120 sample consists of a large number of fine precipitates uniformly and densely distributed in the matrix and sparsely dispersed plate-like precipitates. Figure $6 \mathrm{~b}$ reveals that most of the fine precipitates are GPI zones with a monolayer $\mathrm{Cu}$ atomic plane, while the larger precipitate plates can be readily discerned as two $\mathrm{Cu}$-atom layers sandwiching three Al-atom layers lying on $\{100\}_{\mathrm{Al}}$ planes. In addition, the morphology of the larger precipitate plates is consistent with the previous report of a $\theta^{\prime}$-approximant, which is structurally the same as the $\theta^{\prime}$ phase except for the absence of a $\mathrm{Cu}$ atom in the body center $[27,28]$.

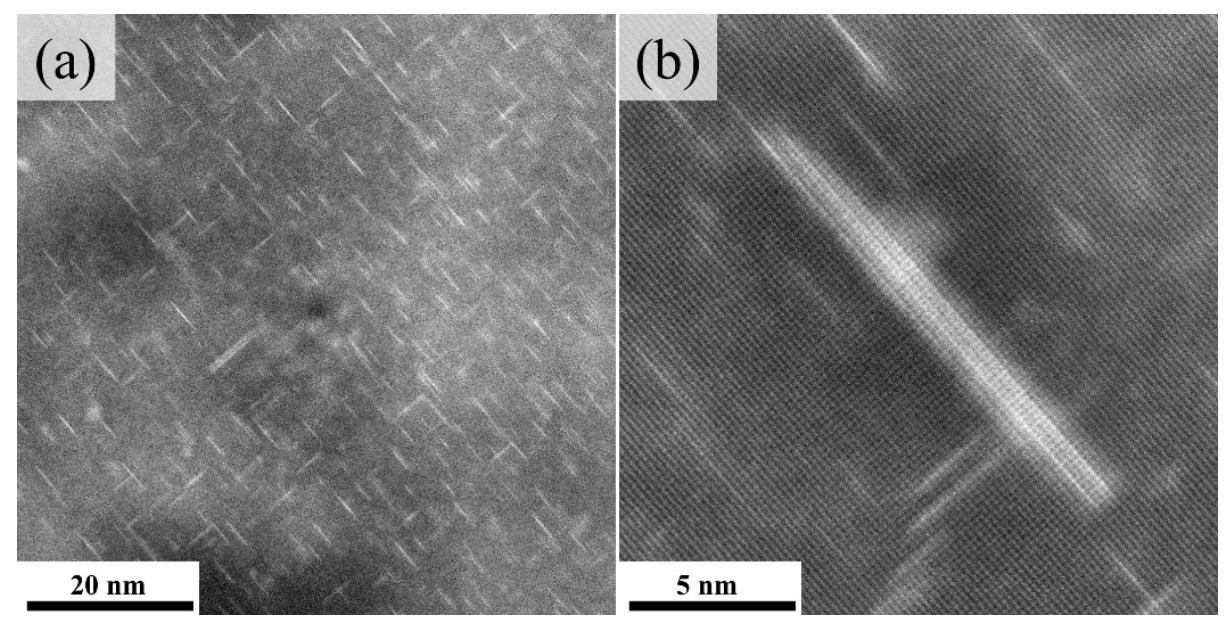

Figure 6. HAADF-STEM images of P80A-120 sample. (a) Low-magnification image. (b) Highresolution image. The electron beam is parallel to $\{001\}_{\mathrm{Al}}$ direction.

\subsection{The Effect of Microstructure Evolution on the Mechanical Properties}

Based on the results shown above, the majority of remnant dislocations were statistically stored dislocations, and these dislocations could significantly interact with the second phase precipitated heterogeneously [43]. Consequently, the microstructure could be altered considerably by changing the degree of large pre-deformation and aging temperature, leading to the enhancement of the mechanical properties. During the aging process, after cold rolling, microstructure evolution occurs via the following processes: Firstly, the solute atoms precipitate heterogeneously from the supersaturated solid solution to form a metastable phase. Secondly, owing to the annihilation of dislocations, the matrix recovers 
to soften the alloy. Thirdly, the precipitated particles may exert a significant pinning effect on the dislocations. All three evolutions occur concurrently and compete during the aging process, determining the final microstructure and mechanical properties of the alloy.

It is well proved that deformation-induced dislocations could significantly accelerate and alter precipitation kinetics via short-circuit diffusion [44,45]. Thus, for the P80A-120 sample, multi-stage precipitates could emerge and coarsen after large pre-deformation despite the aging temperature being relatively lower. The ZL205A alloy has a similar chemical composition to that of the 2219 alloy; therefore, after undergoing large predeformation, the microstructure of the P80A-120 sample also comprised the $\theta^{\prime}$-approximant. In addition, the P80A-120 sample has a more $\theta^{\prime}$ phase than that of the P70A-120 sample because of the larger degree of pre-deformation, as shown in Figure $5 f$,i.

From the variation in Vickers hardness shown in Figure 1b, it can be deduced that the numerous defects introduced by the $70 \%$ degree of pre-deformation could effectively promote the heterogeneous nucleation of precipitates, leading to the continuous enhancement of strength before peak aging. However, with the extension of aging time, the coarsening of the precipitates generally occurred. and the pinning effect declined subsequently, causing a decrease in strength. When the degree of pre-deformation was up to $80 \%$, the dispersive precipitates with higher density could not only compensate for the strength reduction caused by the recovery but also further exert a persistent pinning effect on the movement of dislocations, maintaining the high strength as the rolling state. When the sample underwent $90 \%$ degree of pre-deformation, the drop in hardness at the early stage of aging could be ascribed to the fast dislocation annihilation for the higher free energy.

The tensile yield strength can be expressed using the "composite" Hall-Petch relationship as given below [46]:

$$
\sigma_{Y}=\sigma_{0}^{A l}+\sigma_{S S}+\sigma_{G B}+\sigma_{p}+\sigma_{d}
$$

where $\sigma_{0}^{A l}$ is the resistance to dislocation glide within the crystallite for pure $\mathrm{Al}$, which was reported to be about $10 \mathrm{MPa}$ [47]; $\sigma_{S S}$ is the solution strengthening caused by dissolved solute atoms; $\sigma_{p}$ is the particle strengthening; and $\sigma_{d}$ and $\sigma_{G B}$ are attributed to dislocation strengthening. Among these factors, $\sigma_{G B}$ is a similar value in all specimens for the reason that the specimens contained the same concentration of elements and were also subjected to the same solution treatment to dissolve the majority of soluble phases. Furthermore, the contribution from GB strengthening to $\sigma_{Y}$ is calculated as below [47]:

$$
\sigma_{G B}=k_{y} d_{G B}^{-\frac{1}{2}}
$$

where $k_{y}$ is the Hall-Petch slope, which is almost the same in all specimens, and $d_{G B}$ is the distance between boundaries. As shown in Figure 3d,e, after cold rolling, the grains were stretched, and the distance between the extended boundaries was at least twice the solid solution state. Thus, this suggests that the Hall-Petch GB strengthening mechanism term has less contribution to $\sigma_{Y}$ along the rolling direction in the P70A-120 and P80A-120 samples than in the T6 sample.

According to the results of the tensile test (Figure 2a) and the corresponding microstructures (Figures 5 and 6), it can be revealed that achieving the appropriate coexistence of high-density dislocations and dispersive fine precipitates benefits a better strengthening effect from the combination of dislocation hardening $\left(\sigma_{d}\right)$ and precipitation hardening $\left(\sigma_{p}\right)$. Among the samples under different processing parameters, the microstructure of the P80A-120 sample has the best matching of the remnant dislocations and a variety of beneficial precipitates, such as $\theta^{\prime}$, leading to the highest strength among all the samples.

The fracture morphologies are shown in Figure 7, revealing the variation in ductility. In the T6 sample, the fracture mode was a mix of intergranular and transgranular, which exhibited a considerable number of intergranular cracks and dimples associated with some coarse dimples. According to the Al-Cu phase diagram, after solution treatment at $538^{\circ} \mathrm{C}$, the $\mathrm{Al}_{2} \mathrm{Cu}$ phase will be in equilibrium with the matrix [48], meaning that the particles 
observed in fracture surfaces were coarse $\mathrm{Al}_{2} \mathrm{Cu}$ particles that exist in all specimens. However, for the alloy subjected to large pre-deformation, some coarse particles could be broken down and lessened, which effectively reduced the cracking tendency. Furthermore, it can be observed that the number of the particles in the fracture surfaces is high; thus, we cannot attribute these particles to Fe-containing particles since the studied alloy contains a very low amount of Fe. In comparison, Figure $7 \mathrm{c}-\mathrm{f}$ show that the fracture mode of P70A-120 and P80A-120 were transformed into a mainly transgranular fracture, and the average size of the dimples was smaller.
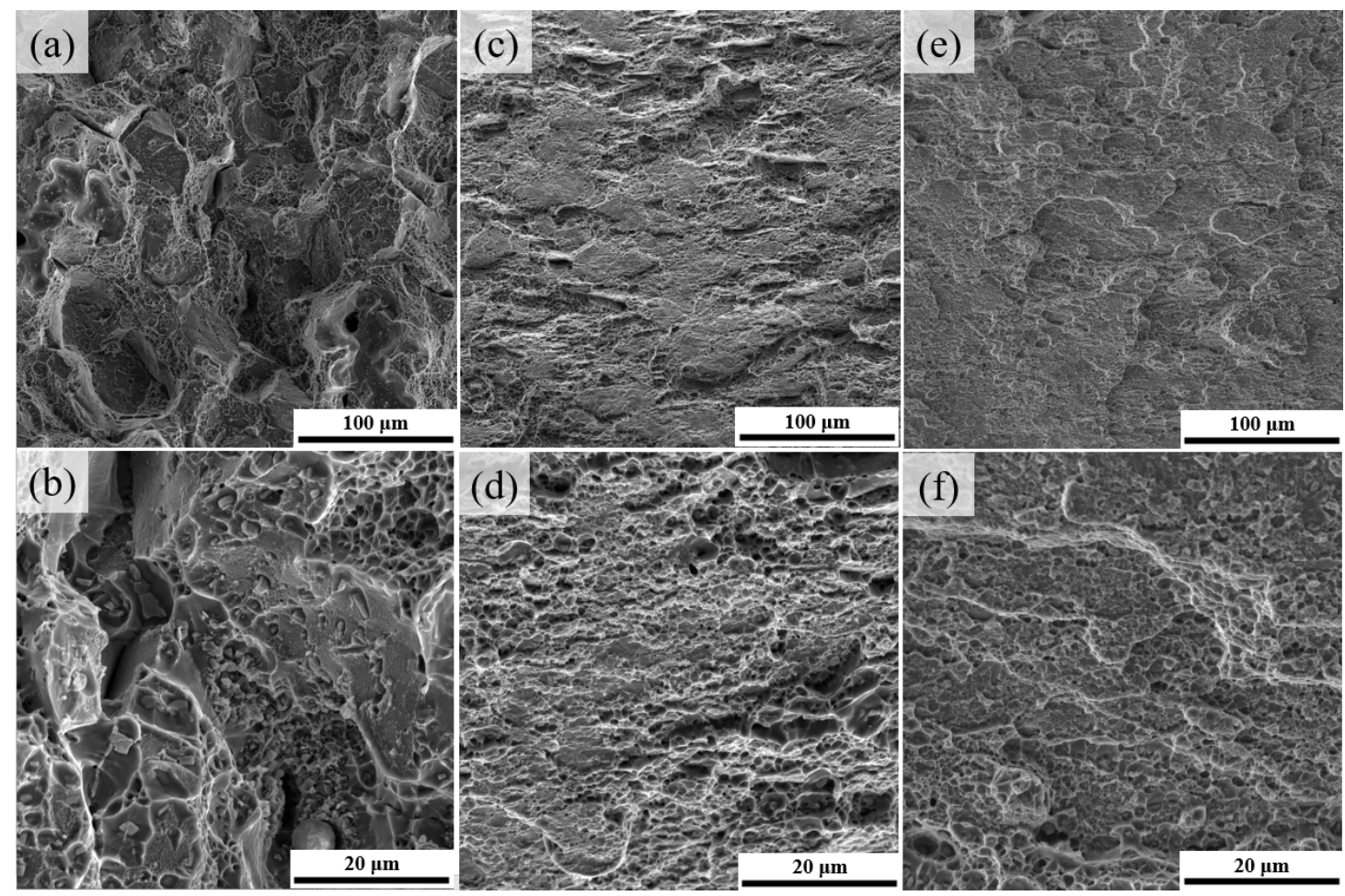

Figure 7. Fracture morphologies of the (a,b) T6 state, (c,d) P70A-120 state, and (e,f) P80A-120 state, corresponding to the samples that underwent uniaxial tensile testing as shown in Figure 4.

The fracture morphologies coincided with the previous analysis of mechanical properties. As shown in Figure 2a, the P70-120 sample and P80-120 presented outstanding ductility in the tensile tests, especially the P70-120 sample, which has nearly twice the ETF than that of the T6 sample. This significant increase in ductility was caused by two optimized microstructures that formed during aging. The first was the decrease in dislocation density because of the recovery, leaving more free paths for dislocation slip and accumulation, which certainly increased the work-hardening rate of the cold-rolled state during tensile testing [39]. The second was the high density of multiple nano-sized precipitates on the matrix without PFZs along the grain boundaries. For the T6 sample, both the weakened PFZs (Figure 5c) and coarse intergranular precipitates (Figure 3c) could easily produce stress concentration near the grain boundaries [49,50]. Significantly, aging after the large degree of pre-deformation could generally prevent the emergence of PFZs along the grain boundaries [51]. Meanwhile, as shown in Figure 6b, the microstructure of the P80A-120 sample has multiple precipitates, such as GP zones, $\theta^{\prime}$-approximant and $\theta^{\prime}$, composed of shear-resistant and shearable precipitates to simultaneously increase the yield strength and uniform ductility. For example, the high density of nano-sized $\theta^{\prime}$ precipitates can provide effective sites for trapping and accumulating dislocations to enhance strength. In addition, the strain-induced dissolution of GP zones and the repartition of solutes to the matrix could contribute to the enhanced strain hardening and, therefore, are responsible for the improvement in plasticity [52]. Finally, the optimized microstructure could sustain the 
work hardening rate and alleviate the tendency of the intergranular cracking, leading to an improvement in the comprehensive mechanical properties of the ZL205A alloy.

\section{Conclusions}

In summary, we demonstrated a TMT approach for the control of precipitations in a casting Al-Cu-Mn alloy (ZL205A) to simultaneously increase strength and ductility by optimizing the process parameters. The mechanical properties and the microstructures were systematically analyzed. Surprisingly, the mechanical properties obtained here (UTS $569 \mathrm{MPa} / 585 \mathrm{MPa}$ with ETF 16.32\%/12.35\%) were superior to other wrought Al-CuMn alloys, such as the 2219 alloy. The strengthening and toughening mechanism was investigated via SEM and TEM. In the current study, the optimized TMT for the ZL205A alloy was peak aging at $120{ }^{\circ} \mathrm{C}$ after a $70-80 \%$ degree of cold rolling in order to induce heterogeneous precipitation and restored dislocations concurrently. The combination of high strength and ductility was ascribed to the formation of multimodal precipitates, including the shearable GP zones/ $\theta^{\prime}$-approximant and shear-resistance $\theta^{\prime}$. The approach described here could be applicable to other $\mathrm{Al}$ alloys whose plasticity of solutionized state allows the conduction of large pre-deformation before aging, even for casting alloys.

Author Contributions: Conceptualization, L.L. and Z.W.; methodology, L.L.; software, Z.Y.; validation, L.L., Z.W. and Q.W.; formal analysis, L.L.; investigation, L.L.; resources, K.Z.; data curation, X.F.; writing-original draft preparation, L.L.; writing—review and editing, Z.W.; visualization, Z.W. and J.L; supervision, J.L. and J.W.; project administration, J.W.; funding acquisition, J.W. All authors have read and agreed to the published version of the manuscript.

Funding: The work was supported by National Natural Science foundation of China (No. 52122509) and the Research Fund of the State Key Laboratory of Solidification Processing (NPU), China (Grant No. 2020-TS-06, 2021-TS-02).

Institutional Review Board Statement: Not applicable.

Informed Consent Statement: Not applicable.

Data Availability Statement: The data used to support the findings of this study are available from the corresponding author upon request.

Acknowledgments: L.L. sincerely thanks Y.L. for advice regarding article preparation.

Conflicts of Interest: The authors declare that they have no conflict of interest.

\section{References}

1. Santos, M.C.; Machado, A.R.; Sales, W.F.; Barrozo, M.A.S.; Ezugwu, E.O. Machining of aluminum alloys: A review. Int. J. Adv. Manuf. Technol. 2016, 86, 3067-3080. [CrossRef]

2. Surekha, K.; Murty, B.S.; Rao, K.P. Comparison of corrosion behaviour of friction stir processed and laser melted AA 2219 aluminium alloy. Mater. Des. 2011, 32, 4502-4508. [CrossRef]

3. Gu, G.; Ye, L.Y.; Jiang, H.C.; Sun, D.X.; Zhang, P.; Zhang, X.M. Effects of T9I6 thermo-mechanical process on microstructure, mechanical properties and ballistic resistance of 2519A aluminum alloy. Trans. Nonferrous Met. Soc. China 2014, 24, 2295-2300. [CrossRef]

4. Guo, T.; Wang, B.; Zhang, Z.; Sun, Q.; Jin, Y.; Ding, W. Effect of micro-scale er on the microstructure and fluidity of ZL20 alloy. Materials 2019, 12, 1688. [CrossRef]

5. Liu, B.; Huang, W.M.; Huang, L.; Wang, H.W. Size-dependent compression deformation behaviors of high particle content B 4C/Al composites. Mater. Sci. Eng. A 2012, 534, 530-535. [CrossRef]

6. Li, M.; Wang, H.; Wei, Z.; Zhu, Z. The effect of Y on the hot-tearing resistance of Al-5 wt.\% Cu based alloy. Mater. Des. 2010, 31, 2483-2487. [CrossRef]

7. Ma, T.; Ge, J.; Chen, Y.; Jin, T.; Lei, Y. Observation of in-situ tensile wire-arc additively manufactured 205A aluminum part: 3D pore characteristics and microstructural evolution. Mater. Lett. 2019, 237, 266-269. [CrossRef]

8. Luo, L.; Luo, L.; Su, Y.; Su, L.; Wang, L.; Guo, J.; Fu, H. Optimizing microstructure, shrinkage defects and mechanical performance of ZL205A alloys via coupling travelling magnetic fields with unidirectional solidification. J. Mater. Sci. Technol. 2021, 74, 246-258. [CrossRef]

9. Lu, G.; Chen, Y.; Yan, Q.; Huang, P.; Zhan, H.X.; Duan, Y. Effects of continuous and pulsed ultrasonic treatment on microstructure and microhardness in different vertical depth of ZL205A castings. Materials 2020, 13, 4240. [CrossRef] 
10. Zhang, M.; Zhang, W.W.; Zhao, H.D.; Zhang, D.T.; Li, Y.Y. Effect of pressure on microstructures and mechanical properties of Al-Cu-based alloy prepared by squeeze casting. Trans. Nonferrous Met. Soc. China 2007, 17, 496-501. [CrossRef]

11. Li, B.; Shen, Y.; Hu, W. Casting defects induced fatigue damage in aircraft frames of ZL205A aluminum alloy-A failure analysis. Mater. Des. 2011, 32, 2570-2582. [CrossRef]

12. Vishnu, P.; Mohan, R.R.; Sangeethaa, E.K.; Raghuraman, S.; Venkatraman, R. A review on processing of aluminium and its alloys through Equal Channel Angular Pressing die. Mater. Today Proc. 2020, 21, 212-222. [CrossRef]

13. Mazurina, I.; Sakai, T.; Miura, H.; Sitdikov, O.; Kaibyshev, R. Grain refinement in aluminum alloy 2219 during ECAP at $250{ }^{\circ} \mathrm{C}$. Mater. Sci. Eng. A 2008, 473, 297-305. [CrossRef]

14. Murty, S.V.S.N.; Sarkar, A.; Narayanan, P.R.; Venkitakrishnan, P.V.; Mukhopadhyay, J. Microstructure and micro-texture evolution during large strain deformation of aluminium alloy AA 2219. Mater. Sci. Eng. A 2016, 677, 41-49. [CrossRef]

15. Mazurina, I.; Sakai, T.; Miura, H.; Sitdikov, O.; Kaibyshev, R. Effect of deformation temperature on microstructure evolution in aluminum alloy 2219 during hot ECAP. Mater. Sci. Eng. A 2008, 486, 662-671. [CrossRef]

16. Liu, M.; Zheng, R.; Li, J.; Ma, C. Achieving ultrahigh tensile strength of $1 \mathrm{GPa}$ in a hierarchical nanostructured $2024 \mathrm{Al}$ alloy. Mater. Sci. Eng. A 2020, 788, 139576. [CrossRef]

17. Shanmugasundaram, T.; Murty, B.S.; Sarma, V.S. Development of ultrafine grained high strength Al-Cu alloy by cryorolling. Scr. Mater. 2006, 54, 2013-2017. [CrossRef]

18. Xie, H.; Wang, M.P.; Chen, W.; Jia, Y. Microstructure, Mechanical Properties, and Texture Evolution of Aluminum Alloy 7005 by Accumulative Roll Bonding. J. Mater. Eng. Perform. 2016, 25, 1199-1210. [CrossRef]

19. Guo, T.B.; Li, Q.; Wang, C.; Wei, S.R.; Wu, Y.B. Effect of equal channel angular pressing on microstructure and mechanical properties of ZL205A alloy. Mater. Sci. Forum. 2018, 913, 77-82. [CrossRef]

20. Mckenzie, P.W.J.; Lapovok, R. ECAP with back pressure for optimum strength and ductility in aluminium alloy 6016 . Part 2: Mechanical properties and texture. Acta Mater. 2010, 58, 3212-3222. [CrossRef]

21. Wang, Y.M.; Ma, E. Strain hardening, strain rate sensitivity, and ductility of nanostructured metals. Mater. Sci. Eng. A 2004, 375, 46-52. [CrossRef]

22. Wang, H.Y.; Yu, Z.P.; Zhang, L.; Liu, C.G.; Zha, M.; Wang, C.; Jiang, Q.C. Achieving high strength and high ductility in magnesium alloy using hard-plate rolling (HPR) process. Sci. Rep. 2015, 5. [CrossRef] [PubMed]

23. An, L.H.; Cai, Y.; Liu, W.; Yuan, S.J.; Zhu, S.Q.; Meng, F.C. Effect of pre-deformation on microstructure and mechanical properties of 2219 aluminum alloy sheet by thermomechanical treatment. Trans. Nonferrous Met. Soc. China 2012, 22, s370-s375. [CrossRef]

24. Lu, Y.; Wang, J.; Li, X.; Chen, Y.; Zhou, D.; Zhou, G.; Xu, W. Effect of pre-deformation on the microstructures and properties of 2219 aluminum alloy during aging treatment. J. Alloys Compd. 2017, 699, 1140-1145. [CrossRef]

25. Wang, H.; Yi, Y.; Huang, S. Influence of pre-deformation and subsequent ageing on the hardening behavior and microstructure of 2219 aluminum alloy forgings. J. Alloys Compd. 2016, 685, 941-948. [CrossRef]

26. Li, X.; Lei, K.; Song, P.; Liu, X.; Zhang, F.; Li, J.; Chen, J. Strengthening of Aluminum Alloy 2219 by Thermo-mechanical Treatment. J. Mater. Eng. Perform. 2015, 24, 3905-3911. [CrossRef]

27. Ma, P.P.; Liu, C.H.; Wu, C.L.; Liu, L.M.; Chen, J.H. Mechanical properties enhanced by deformation-modified precipitation of $\theta^{\prime}$-phase approximants in an Al-Cu alloy. Mater. Sci. Eng. A 2016, 676, 138-145. [CrossRef]

28. Liu, C.; Ma, Z.; Ma, P.; Zhan, L.; Huang, M. Multiple precipitation reactions and formation of $\theta^{\prime}$-phase in a pre-deformed Al-Cu alloy. Mater. Sci. Eng. A 2018, 733, 28-38. [CrossRef]

29. Lu, Y.; Wang, J.; Li, X.; Li, W.; Li, R.; Zhou, D. Effects of pre-deformation on the microstructures and corrosion behavior of 2219 aluminum alloys. Mater. Sci. Eng. A 2018, 723, 204-211. [CrossRef]

30. Dong, F.; Yi, Y.; Huang, S.; He, H.; Huang, J.; Wang, C.; Huang, K. Refinement of second-phase particles and grain structures of $2219 \mathrm{Al}[\mathrm{sbnd}] \mathrm{Cu}$ alloy forgings using an improved thermomechanical treatment process. Mater. Charact. 2021, $173,110927$. [CrossRef]

31. Guo, W.; He, H.; Yi, Y.; Huang, S.; Mao, X.; Fang, J.; Huang, J. Effects of axial cold-compression on microstructure uniformity and mechanical property enhancement of large 2219 Al-Cu alloy rings. Mater. Sci. Eng. A 2020, 798, 140233. [CrossRef]

32. He, H.; Yi, Y.; Huang, S.; Zhang, Y. Effects of cold predeformation on dissolution of second-phase $\mathrm{Al}_{2} \mathrm{Cu}_{\text {particles during solution }}$ treatment of $2219 \mathrm{Al}-\mathrm{Cu}$ alloy forgings. Mater. Charact. 2018, 135, 18-24. [CrossRef]

33. Wang, H.; Yi, Y.; Huang, S. Microstructure Evolution and Mechanical Properties of 2219 Al Alloy During Aging Treatment. J. Mater. Eng. Perform. 2017, 26, 1475-1482. [CrossRef]

34. Dong, F.; Yi, Y.; Huang, C.; Huang, S. Influence of cryogenic deformation on second-phase particles, grain structure, and mechanical properties of Al-Cu-Mn alloy. J. Alloys Compd. 2020, 827, 154300. [CrossRef]

35. Guo, W.; Yi, Y.; Huang, S.; Mao, X.; Fang, J.; He, H.; Hu, B. Effects of deformation temperature on the evolution of second-phase and mechanical properties of large 2219 Al-Cu alloy rings. Mater. Charact. 2020, 160, 110094. [CrossRef]

36. He, H.; Yi, Y.; Huang, S.; Guo, W.; Zhang, Y. Effects of thermomechanical treatment on grain refinement, second-phase particle dissolution, and mechanical properties of $2219 \mathrm{Al}$ alloy. J. Mater. Process. Technol. 2020, 278, 116506. [CrossRef]

37. Zuiko, I.; Kaibyshev, R. Deformation structures and strengthening mechanisms in an Al-Cu alloy subjected to extensive cold rolling. Mater. Sci. Eng. A 2017, 702, 53-64. [CrossRef]

38. Belov, N.A.; Akopyan, T.K.; Shurkin, P.K.; Korotkova, N.O. Comparative analysis of structure evolution and thermal stability of commercial AA2219 and model Al-2 wt \%Mn-2 wt\%Cu cold rolled alloys. J. Alloys Compd. 2021, 864, 158823. [CrossRef] 
39. Cheng, S.; Zhao, Y.H.; Zhu, Y.T.; Ma, E. Optimizing the strength and ductility of fine structured $2024 \mathrm{Al}$ alloy by nano-precipitation. Acta Mater. 2007, 55, 5822-5832. [CrossRef]

40. Liu, L.; Chen, J.H.; Wang, S.B.; Liu, C.H.; Yang, S.S.; Wu, C.L. The effect of Si on precipitation in Al-Cu-Mg alloy with a high $\mathrm{Cu} / \mathrm{Mg}$ ratio. Mater. Sci. Eng. A 2014, 606, 187-195. [CrossRef]

41. Bourgeois, L.; Dwyer, C.; Weyland, M.; Nie, J.F.; Muddle, B.C. Structure and energetics of the coherent interface between the $\theta^{\prime}$ precipitate phase and aluminium in Al-Cu. Acta Mater. 2011, 59, 7043-7050. [CrossRef]

42. Moshtaghi, M.; Safyari, M.; Hojo, T. Effect of solution treatment temperature on grain boundary composition and environmental hydrogen embrittlement of an Al-Zn-Mg-Cu alloy. Vacuum 2021, 184, 109937. [CrossRef]

43. Moshtaghi, M.; Safyari, M.; Kuramoto, S.; Hojo, T. Unraveling the effect of dislocations and deformation-induced boundaries on environmental hydrogen embrittlement behavior of a cold-rolled Al-Zn-Mg-Cu alloy. Int. J. Hydrog. Energy 2021, 46, 8285-8299. [CrossRef]

44. Fujita, S. Statistical mechanical theory of fast interstitial diffusion in metals. J. Phys. Chem. Solids 1988, 49, 41-46. [CrossRef]

45. Cermak, J.; Stloukal, I.; Ruzickova, J.; Pokorna, A. Short-circuit diffusion in NiAl alloys. Intermetallics 1998, 6, 21-28. [CrossRef]

46. Safyari, M.; Moshtaghi, M.; Hojo, T.; Akiyama, E. Mechanisms of hydrogen embrittlement in high-strength aluminum alloys containing coherent or incoherent dispersoids. Corros. Sci. 2022, 194, 109895. [CrossRef]

47. Malopheyev, S.; Kulitskiy, V.; Kaibyshev, R. Deformation structures and strengthening mechanisms in an Al-Mg-Sc-Zr alloy. J. Alloys Compd. 2017, 698, 957-966. [CrossRef]

48. Safyari, M.; Moshtaghi, M.; Kuramoto, S. Environmental hydrogen embrittlement associated with decohesion and void formation at soluble coarse particles in a cold-rolled Al-Cu based alloy. Mater. Sci. Eng. A 2021, 799, 139850. [CrossRef]

49. Morgeneyer, T.F.; Starink, M.J.; Wang, S.C.; Sinclair, I. Quench sensitivity of toughness in an Al alloy: Direct observation and analysis of failure initiation at the precipitate-free zone. Acta Mater. 2008, 56, 2872-2884. [CrossRef]

50. Ogura, T.; Hirosawa, S.; Cerezo, A.; Sato, T. Atom probe tomography of nanoscale microstructures within precipitate free zones in Al-Zn-Mg(-Ag) alloys. Acta Mater. 2010, 58, 5714-5723. [CrossRef]

51. Guo, C.; Zhang, H.; Li, S.; Chen, R.; Nan, Y.; Li, L.; Wang, P.; Li, B.; Cui, J.; Nagaumi, H. Evolution of microstructure, mechanical properties and corrosion behavior of $\mathrm{Al}-4 \mathrm{Mg}-2 \mathrm{Zn}-0.3 \mathrm{Ag}$ (wt.\%) alloy processed by $\mathrm{T} 6$ or thermomechanical treatment. Corros. Sci. 2021, 188, 109551. [CrossRef]

52. Chen, B.A.; Liu, G.; Wang, R.H.; Zhang, J.Y.; Jiang, L.; Song, J.J.; Sun, J. Effect of interfacial solute segregation on ductile fracture of Al-Cu-Sc alloys. Acta Mater. 2013, 61, 1676-1690. [CrossRef] 